\title{
LA PERTINENCIA DE LAS CIENCIAS SOCIALES: EN TORNO A LA LUCHA CONTRA EL DELITO
}

\author{
JAIME ARAUjo Frías \\ UNIVERSIDAD INCA GARCILASO DE LA VEGA \\ jaimearaujofrias@hotmail.com
}

\section{RESUMEN}

La clase política y la población en general siguen creyendo que el castigo es un instrumento eficaz para la lucha contra el delito. Sin embargo investigaciones actuales sugieren que esta medida no sólo ha sido y sigue siendo inútil en la lucha contra el delito, sino que también es el estímulo más poderoso. De otro lado las respuestas más efectivas que se han dado y se sugieren para la lucha contra el delito es la garantía y satisfacción de los derechos sociales.

Palabras Clave: Delito, castigo, cárcel, desigualdad, Ciencias Sociales.

\begin{abstract}
Politicians and the general public still believe that punishment is an effective tool in the fight against crime. But current research suggests that this measure not only has been and is still useless in the fight against crime, but also is the most powerful stimulus. On the other hand the most effective responses that have occurred and are suggested to the fight against crime is the assurance and satisfaction of social.
\end{abstract}

KEYWoRDS: Crime, punishment, prison, inequality, social sciences.

El grado de civilización en una sociedad se juzga visitando sus cárceles.

Fiodor, DOSTOIEVSKI, La casa de los muertos.

\section{INTRODUCCIÓN}

Siempre me ha interesado saber cuál es la función de la cárcel realmente. No me satisface el bien intencionado objetivo contenido en el artículo II, de nuestro Código de Ejecución Penal, el cual a la letra dice, «tiene por objeto la reeducación, rehabilitación y reincorporación del penado a la sociedad». Ello por razones obvias. Mucho de nosotros tal vez habrá tenido la experiencia de algún conocido, amigo o en el peor de los casos un familiar, que luego de haber cumplido una condena de meses o años ya sea por haber sido culpable o inocente, puesto que, de las dos maneras se manda a la cárcel a una persona, la primera es legítima, la segunda un error legal; salga no solo no reeducado ni rehabilitado, sino más bien experto en el oficio del crimen. 
El presente ensayo de reflexión es producto de alguna manera de esa curiosidad que me embarga y de la cual poco se dice porque estamos acostumbrados a dar por supuesto que las cosas están bien como están. Espero aportar algunos alcances que incite a la reflexión respecto del delito y de las medidas que se tomen para hacerle frente al delito de la mano de algunos aporte hechas por los investigadores sociales.

\section{CRimen y CASTigo}

Últimamente somos testigos de un escenario cada más vez más siniestro protagonizado por la delincuencia y la inseguridad ciudadana. Las respuestas ofrecidas por las autoridades de turno, a saber: aumento de la represión policial, endurecimiento de las penas y aumento del presupuesto para la compra de instrumentos tecnológicos de vigilancia, son las que se han puesto en marcha desde las esferas políticas. De otro lado, dichas iniciativas son alentadas por la población en general, pues el miedo que se ha instalado ante el crimen es cada vez mayor, lo que hace que la población sea partidaria de medidas punitivas cada vez más drásticas.

En este estado de la cuestión cabe preguntarnos sobre el papel de las ciencias sociales, dado que es el estudio de estas, la que sirve para mejor conocer la realidad de los problemas sociales que se va a juzgar y sobre las cuales se tiene que tomar decisiones a fin de ser resueltos. Porque, una cosa es saber después de haber investigado y reflexionado, otra muy distinta es adoptar medidas que nadie discute para no tener que investigar. Es posible que la razón de medidas ineficaces para enfrentar el delito tenga que ver con la limitación de nuestra comprensión del delito. La idea generalizada de que es un pecado que hay que castigar antes que prevenir. «Esta actitud retributiva enraizada en el deseo primitivo de venganza, bloquea tanto la búsqueda de los mecanismos del delito como el diseño de programas eficaces de prevención y rehabilitación» (Bunge 2008: 49).

Son las ideas las que hacen que las personas se maten unas a otras. Ideas sobre cómo son los demás o, sobre quienes somos nosotros o, sobre cómo defender nuestros intereses o nuestros derechos son las que nos llevan a violar los acuerdos de convivencia pacífica, a convertirnos en opresores en nombre de la justicia, a construir nuestra seguridad sobre la inseguridad de muchos.

En este sentido, los saberes y la reflexión crítica que nos aportan las ciencias sociales son muy importantes porque de ello depende nuestra práctica: Lo que pensamos sobre las cosas que hacemos influye en nuestro modo de hacerlas, o incluso en si lo hacemos o no. Y como dice Bunge:

Quien quiera que se interese seriamente en reducir la tasa de delincuencia, en lugar de librar vocíferas pero ineficaces «guerras al crimen», intentará descubrir las causas del delito con el fin de rediseñar políticas sociales en lugar de ensañarse en el castigo, particularmente sabiendo que la cárcel tradicional es una escuela de delincuencia (Bunge 2008: 49).

Son precisamente las ciencias sociales, particularmente la antropología, la sociología, la psicología social, la criminología, entre otras, las que nos dicen por ejemplo que la lucha contra la delincuencia no pasa por ensañarse contra la persona que ha cometido un crimen, sino por crear las condiciones sociales que posibiliten las oportunidades y condiciones para el desarrollo del particular proyecto de vida. Pues cabe recordar que el ejercicio del poder punitivo ejercido a través de la ley penal fue creado a fin de ser la última alternativa para regular la conducta social y no la primera como parece ser el criterio de nuestras autoridades. «El Derecho fue creado para proteger, en última instancia, la libertad personal, a fin de que cada ser humano, dentro del bien común pueda realizarse en forma integral, es decir, pueda cumplir con su singular proyecto de vida [...]» (Fernández Sessarego 2005: 8).

En este sentido, investigadores sociales indican que: a). La cárcel no sólo es ineficaz, sino que exacerba el delito; y que b). La garantía de los derechos vitales es un freno para el del delito. Veamos cada una de ellas. 


\section{LA CÁRCEL NO SÓLO ES INEFICAZ SINO QUE EXACERBA EL DELITO}

A lo largo de la historia de la humanidad, el castigo ha constituido una sanción de diverso grado de dureza y con manifestaciones variadas. Por ejemplo, en la antigüedad se dice que primó la «ley del talión» más conocida como la ley del «ojo por ojo y diente por diente»; posteriormente el castigo adquirió un carácter formal, correspondiéndole al Estado, la delimitación e imposición del mismo: la cárcel.

La cárcel, como toda institución social, es una creación propia del modelo económico y social, y por tanto, no es ni un mal necesario, ni algo inevitable, sino simplemente, una realidad fabricada históricamente que hemos de situar dentro de las estructuras políticas de la sociedad encargadas de funciones básicas de legitimación, organización y control de la vida social. Actualmente la cárcel es el justo castigo que por antonomasia se aplica a la persona que ha cometido un delito a fin de acotarlo y ofrecer seguridad a la sociedad. Sin embargo esta práctica retributiva no ha logrado con la tan ansiada reducción de los delitos. Por el contrario, la institución de la cárcel es un medio reproductor de mayor violencia (Zaffaroni 1991: 51). Entonces, ¿por qué seguir manteniendo una institución que se nos ofrece como ineficaz para nuestros fines?

Tal vez la tasa de encarcelamiento elevada y el trato duro a los delincuentes parecieran lógicos si la prisión se demostrase útil para reducir los delitos y proteger a los ciudadanos. Por el contrario, los expertos parecen de acuerdo en que no funciona muy bien. Por ejemplo, Wilkinson y Pickett citando al psiquiatra penitenciario James Gilligan dicen que «la manera más efectiva de convertir a una persona no violenta en violenta es mandarla a prisión» (2009: 178) y luego concluye que:

La justicia criminal y los sistemas penales están funcionado sobre la base de un gran error, que consiste básicamente en creer que el castigo sirve para prevenir o inhibir la violencia, cuando es el estímulo más poderoso que se conoce hasta el momento (Wilkinson et al. 2009: 52).

La tesis de que el castigo es inútil para controlar el delito ya había sido intuido por pensadores atentos como Beccaria y Paine, quienes eran consciente de la relación existente entre la forma de la organización social y la aplicación de castigos. Argüían de alguna manera que la existencia de injustas desigualdades sociales en el plano económico era mantenida por gobiernos que recurría a la justicia penal para conservar los privilegios adquiridos. Además eran conscientes de la inutilidad del castigo para evitar los delitos, y de la imperiosa necesidad de reformas sociales para garantizar la paz social (Poulastrou 2004: 48).

Estudios actuales realizados sobre la relación entre el delito y la desigualdad muestra que los países más desiguales tienen tasas de encarcelamiento más altas que los más igualitarios, tal es el caso por ejemplo de países con mayor igualdad social como Japón y Finlandia, cuyas poblaciones carcelarias son las más bajas del mundo en contraste con los Estados Unidos cuya población carcelaria es la más alta del mundo. La conclusión es evidente, en las sociedades más desiguales, el dinero que debería destinarse a bienestar, educación, salud, etc.; se invierte en reformas en el sistema judicial y penal (Wilkinson et al. 2009: 172-179).

Tales investigaciones sugieren ser tenidas en cuenta puesto que de otro modo seguiremos manteniendo una medida que en el mejor de los casos mantiene el problema tal como está y en el peor de los casos los agudizan.

\section{LA GARANTÍA DE LOS DERECHOS SOCIALES ES UN FRENO PARA EL DEL DELITO}

Una idea generalizada de las autoridades que toman las decisiones políticas es que la calidad de un sistema político se mide por el Producto Bruto Interno, cuyo aumento terminaría por favorecer a los más pobres. Ocurre en cambio que el simple aumento de la riqueza como sea genera en todo caso el 
crecimiento de la desigualdad, cuya percepción, más allá de ciertos límites, es aún más intolerable que la pobreza (Ferrajoli 2011: 67). Es el caso por ejemplo de países ricos como Estados Unidos, donde la población carcelaria ha aumentado de forma constante desde principios de la década de 1970. En 1978 había más de 450.000 personas en la cárcel, pero en el 2005 ya eran más de dos millones, las cifras se habían duplicado. De otro lado, en Reino Unido, los números se han duplicado desde 1990, pasando de alrededor de 46.000 reclusos a 80.000 en el 2007 (Wilkinson et al. 2009: 169).

La situación actual de uno de los países más ricos del mundo (pero el mas desigual) como Estados Unidos muestra que «el 1\% de la población disfruta de las mejores viviendas, la mejor educación, los mejores médicos y el mejor nivel de vida, pero hay una cosa que el dinero no puede comprar: la comprensión de que su destino está ligado a cómo vive el otro 99\%» (Stiglitz 2012: 23). A lo largo de la historia esto es algo que esa minoría solo ha logrado entender cuando ya era demasiado tarde, pues:

Las consecuencias de la desigualdad son conocidas: altos índices de criminalidad, problemas sanitarios, menores niveles de educación, de cohesión social y de esperanza de vida. Los integrantes del 1 por ciento se llevan a casa la riqueza, pero al hacerlo no le han aportado nada más que angustia e inseguridad al 99 por ciento. Sencillamente, la mayoría de los estadounidenses no se ha beneficiado del crecimiento del país (Stiglitz 2012: 24).

Allí donde no existe la justicia social, donde reina la pobreza, donde predomina la ignorancia y donde se crea en la población sentimientos de represión y venganza contra las personas que han cometido un delito: las personas nunca estaremos seguros.

Esto viene a corroborar por ejemplo que la criminalidad en nuestro país se caracterice por la marcada presencia de internos que solo han cursado nivel de primaria o secundaria. De los cuales, el 24\% ha seguido únicamente el nivel primario, mientras que el 65\% ha logrado el nivel secundario (Informe Estadístico del INPE de diciembre del 2012), a eso hay que agregarle que más del $90 \%$ de la población carcelaria son personas que provienen de familias pobres y disfuncionales.

En consecuencia, se sigue que:

Los políticos en vez de apoyar leyes penales más duras, deben saber que la legislación por sí misma, sin programas sociales diseñados para la reducir la pobreza, elevar el nivel de educación y contribuir a la reinserción en la sociedad, sin duda, no obtendrá grandes resultados o que incluso será contraproducente (Bunge 2009: 454).

La mejor política económica, la más eficaz para promover el desarrollo, así como la mejor política en materia de seguridad y de prevención de los delitos, es una política social dirigida a garantizar los derechos vitales de todos; y que el gasto público necesario para tal fin no ha de concebirse como un costoso pasivo en los balances públicos, sino como la forma de inversión pública más productiva (Ferrajoli 2011: 69).

Ahora bien, la manera más justa y eficiente de combatir el delito no es endurecer el Código Penal o incrementar la fuerza policial:

Esta es la idea bárbara de que la justicia equivale a la venganza. A largo plazo, la manera más eficiente de manejar la criminalidad es atacar las fuentes sociales del delito, tales como las crudas desigualdades en los ingresos, el desempleo, la ignorancia y la anomia (Bunge 2009: $348)$.

Esto de ninguna manera debe ser entendido como una apuesta por la abolición de las cárceles sin más, sino más bien como una crítica a la cárcel tradicional fundada en el castigo en detrimento de la rehabilitación y reinserción de la persona, y de otro lado en la apuesta por la garantía de los derechos 
sociales, tales como: educación, salud, trabajo, vivienda, etc. Pues las estadísticas muestran que la desigualdad en los ingresos y bienes es el indicador más fiable y, en consecuencia, un predictor del índice de criminalidad (Bunge 2009: 150)

Sostengo, que las medidas punitivas y carcelarias deben ser mantenidas, pero deben ser la última instancia a las cuales se deben recurrir cuando se hayan agotado las medidas y reformas sociales. Vale decir cuando la garantía y satisfacción de los derechos sociales se cumplan. Puesto que:

Es absurda la tesis de que los derechos sociales cuestan mucho. Si pensamos en los vistosos incumplimientos de los derechos sociales, en las espantosas bolsas de miseria y en las enormes desigualdades en el mundo e incluso dentro de los países más ricos, debemos por el contrario concluir que cuesta demasiado poco, vergonzosamente poco (Ferrajoli 2011: 67).

Y esto sólo es posible si se toman en serio los derechos sociales, es decir si se abandona el enfoque programático de los derechos sociales y se garantiza realmente su satisfacción en vez de ensañarse contra las personas que cometen delitos sin antes averiguar las causas que los originan.

\section{CONCLUSIÓN}

A lo largo de la presente reflexión he argüido que la represión carcelaria, no sólo es ineficaz para enfrentar el delito, sino que por el contrario se ha demostrado que es un aliciente muy eficaz para reproducirlo. Sin embargo, también he sugerido de la mano de algunos pensadores sociales que las reformas sociales que tienen por objetivo garantizar los derechos sociales deben priorizarse antes que ensañarse contra el delincuente y tomar medidas punitivas que acaban manteniendo el estado de la cuestión y en el peor de los casos agudizando la ola de delitos. La satisfacción de los derechos sociales debe ser la prioridad y el sistema carcelario lo accesorio, de lo contrario las cárceles seguirán siendo las universidades del delito y el ensañamiento contra el delincuente de parte de las autoridades, un buen pretexto para eludir los programas y satisfacción de los derechos sociales.

En consecuencia urge que los que tienen en sus manos el diseño de programas para la lucha contra el delito tomen en cuenta los aportes de las ciencias sociales antes de tomar medidas a espaldas de las mismas. 


\section{BiBLIOGRAFÍA}

\section{BUNGE, Mario}

2009 Filosofía política. Solidaridad, Cooperación y Democracia Integral. Barcelona: Gedisa.

2008 Filosofía y sociedad. México: Siglo XXI.

FERNÁNDEZ SESSAREGO, Carlos

2005 «De la persona y de la sociedad». En: La Constitución comentada. Análisis artículo por artículo, Gaceta Jurídica (ed.). Lima.

FERRAJOLI, Luigi

2011 Principia iuris. Teoría del derecho y de la democracia. 2. Teoría de la democracia. Madrid: Trotta.

POLASTROU, Martín

2004 «Desigualdad social y castigo. Aportes del iluminismo para una criminología radical». En: Rivera Beiras, Iñaki (coordinador) Mitologías y discursos sobre el castigo. Historia del presente y posibles escenarios. Anthropos, Barcelona.

STIGLITZ, Joseph

2012 El precio de la desigualdad. Barcelona: Taurus.

WILKINSON, Richard y PICKETT, Kate

2009 Desigualdad. Un análisis de la (in) felicidad colectiva. Madrid: Turner.

ZAFFARONI, Eugenio Raúl

1991 «La filosofía del derecho penitenciario en el mundo contemporáneo». En: cuadernos de la cárcel, Edición especial de No hay derecho, Buenos Aires. 